\title{
Florística e fitossociologia da vegetação de um campo sujeito à arenização no sudoeste do Estado do Rio Grande do Sul, Brasil ${ }^{1}$
}

\author{
Elisete Maria de Freitas ${ }^{2,3,6}$, Ilsi Iob Boldrini ${ }^{3}$, Sandra Cristina Müller ${ }^{4}$ e Roberto Verdum ${ }^{5}$
}

\author{
Recebido em 24/09/2007. Aceito em 21/08/2008
}

\begin{abstract}
RESUMO - (Florística e fitossociologia da vegetação de um campo sujeito à arenização no sudoeste do Estado do Rio Grande do Sul, Brasil). Extensas áreas de campo nativo do sudoeste do Rio Grande do Sul são suscetíveis ao processo de arenização, que ocorre em áreas de fragilidade pedológica, tendo influência de interferência antrópica e fatores abióticos. Com o objetivo de testar a variação da cobertura vegetal e a dinâmica da arenização no tempo e conforme a influência da distância da encosta, foi desenvolvido um estudo florístico e fitossociológico em áreas de campo nativo sob pastejo. Duas subáreas, diferentes quanto ao processo da arenização, foram selecionadas no município de São Francisco de Assis, RS. O levantamento florístico apontou a ocorrência de 102 espécies, distribuídas em 25 famílias. No estudo fitossociológico, 35 quadros permanentes de $0,25 \mathrm{~m}^{2}$ em cada subárea foram dispostos em diferentes distâncias da encosta do morro. Foram registradas as coberturas das espécies vegetais, do mantilho e do solo exposto em três períodos. Dados sobre riqueza e diversidade de espécies e formas de vida foram avaliados por análise de variância, via testes de aleatorização, considerando o fator temporal e o espacial (distância da encosta). Houve maior redução da diversidade específica e da cobertura vegetal na subárea 1 (com menor cobertura vegetal) conforme a variação temporal. Na subárea 2 (com maior cobertura vegetal), o aumento do solo exposto e a conseqüente redução da cobertura vegetal tiveram maior influência da distância da encosta. A alteração da cobertura vegetal e a expansão da arenização observadas ao longo do tempo são resultado da influência conjunta da dinâmica pluviométrica, do tipo solo, da presença de encostas dos relevos tabulares com pouca vegetação e da contínua pressão de pastejo.
\end{abstract}

Palavras-chave: areais, campo nativo, dinâmica vegetacional, diversidade, Pampa

ABSTRACT - (Floristics and phytosociology of grassland vegetation subject to sandy desertification in southwestern Rio Grande do Sul State, Brazil). Extensive areas of native grassland in southwestern Rio Grande do Sul are susceptible to sandy desertification, which occurs in pedologically fragile areas influenced by anthropic interference and abiotic factors. A floristic and phytosociological study was carried out in grazed native grasslands to test vegetation cover variation and sandy desertification dynamics over time and according to the influence of slope distance. Two sub-areas that differed as to the sandy desertification process were selected in São Francisco de Assis municipality, Rio Grande do Sul. The floristic survey revealed the presence of 102 species, distributed in 25 families. For the phytosociological study, 35 permanent plots $\left(0.25 \mathrm{~m}^{2}\right.$ each $)$ in each sub-area were arranged at different distances from the hillside slope. Cover of plant species and litter, and bare soil were recorded for three periods. Richness, species diversity, and life forms were evaluated by analysis of variance using randomization tests, considering temporal and spatial factors (slope distance). Higher reduction of species diversity and vegetation cover in sub-area 1 (with less vegetation cover) occurred due to temporal variation. In sub-area 2 (with more vegetation cover), the increase in bare soil and a subsequent reduction of vegetation cover were highly influenced by slope distance. Vegetation cover change and sandy desertification expansion observed throughout this period resulted from the joint influence of rainfall dynamics, soil type, presence of tableland slopes with little vegetation, and constant grazing pressure.

Key words: diversity, native grassland, Pampa, sandy areas, vegetation dynamics

\section{Introdução}

O sudoeste do Rio Grande do Sul caracteriza-se por uma paisagem tipicamente campestre, inserida na região do Pampa, porém de extrema fragilidade pedológica, onde há formação de extensas áreas arenosas, por meio de um processo denominado arenização, que é resultado do retrabalhamento de depósitos areníticos (pouco consolidados) ou arenosos (não consolidados) que, devido à constante mobilidade dos sedimentos, dificultam a fixação da vegetação (Suertegaray 1998). Esses depósitos constituem formações superficiais e seu

\footnotetext{
1 Parte da Dissertação de Mestrado da primeira Autora

Museu de Ciências Naturais/UNIVATES, Av. Avelino Talini 171, 95900-000 Lajeado, RS, Brasil

3 Universidade Federal do Rio Grande do Sul, Programa de Pós-Graduação em Botânica, Av. Bento Gonçalves 9500, Prédio 43433, $91501-970$ Porto Alegre, RS, Brasil

4 Universidade Federal do Rio Grande do Sul, Departamento de Ecologia, Av. Bento Gonçalves 9500, Prédio 43422, $91501-970$ Porto Alegre, RS, Brasil

5 Universidade Federal do Rio Grande do Sul, Programa de Pós-Graduação em Geografia, Av. Bento Gonçalves 9500, Prédio 43136, $91501-970$ Porto Alegre, RS, Brasil

6 Autor para correspondência: elicauf@univates.br
} 
retrabalhamento é resultado de uma dinâmica morfogenética em que processos hídricos superficiais, particularmente o escoamento concentrado do tipo ravina ou voçoroca, expõem, transportam e depositam areia sobre a superfície, originando os areais, sendo a areia exposta constantemente removida pela ação do vento (Suertegaray 1998).

O processo de arenização propriamente dito pode ser definido pela morte de plantas e posterior substituição por substrato exposto (areia), caracterizado por uma gradual redução da complexidade e diversidade da vegetação, com conseqüiente aumento de exposição do substrato até $100 \%$ (Trindade 2003). Este processo é um importante fenômeno de degradação ambiental, tendo em vista que extensas áreas de campo são substituídas por areia, ravinas e voçorocas. Em 2000, na região de abrangência dos nos municípios de Alegrete, Cacequi, Itaqui, Maçambará, Manuel Viana, Quaraí, Rosário do Sul, São Borja, São Francisco de Assis e Unistalda, havia registro de 3.663 ha com areais, além de 1.600 ha com focos de arenização (Suertegaray et al. 2001).

A presença e a expansão dos areais no sudoeste sul-rio-grandense são anteriores aos primórdios da colonização e reside na fragilidade natural do ecossistema (Suertegaray 1995; 1998; Marchiori 1992). A aração da terra para uso com lavouras e posterior abandono e o superpastoreio (excesso de carga animal no sistema de pastejo extensivo) estão entre as principais ações humanas que resultam em novos focos ou na expansão acelerada de areais. Isso foi verificado a partir de 1970, quando ocorreu o aumento das lavouras de produtos agrícolas na região,com a conseqüente redução da área destinada ao pastoreio do gado nas propriedades e o superpastoreio do campo em relação aos anos anteriores (Verdum 2004).

A interpretação dos estudos geomorfológicos, associada à dinâmica hídrica e eólica, indica que os areais resultam de processos hídricos, relacionados a uma topografia favorável, que inicialmente permitem a formação de ravinas e voçorocas. Na continuidade, ocorre o alargamento de suas bordas por erosão lateral e regressiva. À jusante, em decorrência do transporte de sedimentos pela água durante chuvas torrenciais, formam-se depósitos arenosos em forma de leque que se agrupam originando um areal. $\mathrm{O}$ vento ocasiona a ampliação desse processo ao movimentar essa areia por todas as direções (Suertegaray et al. 2001).

Os solos da região dos campos com arenização apresentam teores de argila que oscilam entre 6 e $12 \%$ e a acumulação de matéria orgânica varia de 0,1 a 0,7. Esses valores conferem baixa resistência aos processos erosivos, tanto de origem eólica como hídrica, e imprimem reduzida capacidade de retenção de nutrientes essenciais ou de substâncias portadoras destes nutrientes, além de dificultar o armazenamento de água, provocando déficits hídricos mesmo em curtos períodos de estiagem (Klamt \& Schneider 1995). Tais características, associadas à ocorrência de ventos e à má distribuição das chuvas, apesar da média anual de $1.400 \mathrm{~mm}$, criam condições para o aparecimento de processos erosivos. Esses processos estão inclusos, principalmente, na unidade de mapeamento de solos Cruz Alta (Latossolo Vermelho Escuro, com ocorrência de Areias Quartzosas) e também de solos Podzólicos das unidades São Pedro e Santa Maria), manifestando-se predominantemente sobre as formações superficiais (areias quartzosas) (Azevedo \& Kaminski 1995).

A busca de explicações e o levantamento das medidas já adotadas para reduzir ou resolver o "problema" dos areais indicou que os estudos e trabalhos já realizados sempre estiveram associados ao uso de espécies exóticas de interesse comercial, sem considerar as características potenciais da vegetação nativa. Além disso, não existem levantamentos sobre a flora campestre nativa dos campos com arenização, tampouco quantitativos (exceto de Trindade 2003), que pudessem auxiliar na compreensão do processo e sua influência sobre a dinâmica da vegetação nativa, apontando o uso ou a manutenção de espécies regionais como soluções viáveis para a contenção dos areais.

A redução progressiva da cobertura da vegetação ao longo do tempo, como consequiência do aumento das manchas de areias, é evidente. No entanto, não há informações sobre como isso ocorre ao longo do tempo e quais espécies ou grupo de espécies são potencialmente mais resistentes ao avanço da areia. Além disso, o fato de que vários areais ocorrem nas planícies que mantêm contato com as encostas dos morros (cerros) nos conduz a questionar sobre a influência da distância da encosta, pois a presença ou não de cobertura vegetal nas encostas interfere diretamente no impacto da água das chuvas sobre o solo e, assim, no processo de arenização. Diante disso, os objetivos deste trabalho foram testar se houve variação da cobertura vegetal e avanço da arenização durante 10 meses de observação (fator temporal) e qual a influência da distância da encosta (fator espacial) sobre estas variáveis, considerando duas áreas com distinta cobertura vegetal sobre a encosta. Além da dinâmica da cobertura vegetal, foram avaliadas a diversidade de espécies e a participação de formas biológicas conforme os fatores supracitados.

\section{Material e métodos}

O estudo foi realizado num campo da região da Campanha, ao sul da escarpa do Planalto, que faz parte 
da unidade geológica dos sedimentos permotriássicos do sistema sul-brasileiro. Apresenta morros tabulares de arenito, capeados ou não por lavas vulcânicas da Formação Serra Geral, que se repetem em todo o território, como morros testemunhos. Como elementos da vegetação da Campanha são apontadas formações florestais, como capões, mata arbustiva, cordões de galeria, matas palustres e a vegetação dos tabuleiros, e formações abertas, como os campos, os vassourais e o parque do espinilho. No entanto, o campo gramináceo é predominante, quando comparado às demais formações na fisionomia da paisagem (Rambo 1956). Considerando a Classificação da Vegetação Brasileira, a área corresponde às formações de estepe do bioma Pampa (IBGE 2004).

A área de estudo localiza-se na Fazenda de Anair Salbego Bem, na bacia hidrográfica do arroio Inhacundá, em São Francisco de Assis, sudoeste do RS, entre as latitudes $29^{\circ} 00^{\prime}-31^{\circ} 00^{\prime} \mathrm{S}$ e longitudes $54^{\circ} 30^{\prime} \mathrm{W}-58^{\circ} 45^{\prime} \mathrm{W}$ (Fig. 1). Com 95 ha de área, a propriedade é utilizada para a criação de gado extensivo, comportando uma lotação média de 0,51 cabeças por ha. $O$ campo estudado ocorre sobre uma planície formada a partir de depósitos arenosos oriundos da decomposição (formações superficiais) da Formação Botucatu, que faz contato abrupto com a encosta de um morro tabular de arenito silicificado, com $222 \mathrm{~m}$ de altitude.

Para a coleta de dados e análise da composição florística e fitossociológica, foram selecionadas duas áreas do campo em condições diferentes de arenização, denominadas subáreas 1 e 2 . Na subárea 1 , verificava-se o processo de arenização, estando a encosta do cerro voltada para o norte $\left(\mathrm{N} 40^{\circ} \mathrm{O}\right)$ e com pouca cobertura vegetal. Na subárea 2, também existia areia exposta, porém em menor proporção e sem movimentação aparente de solo, estando a encosta do cerro voltada para o sul $\left(\mathrm{S} 20^{\circ} \mathrm{O}\right)$ e completamente coberta por vegetação arbórea. As duas subáreas têm cerca de 2,5 ha cada, apresentam características distintas com relação ao processo de arenização e estão separadas por um areal.

Para caracterização local, foram coletadas 10 amostras de solo, tomadas ao acaso, em cada subárea sobre toda a sua extensão, para a constituição de uma amostra composta para posterior análise química e estrutural, seguindo o método da Sociedade Brasileira de Ciência de Solo (Embrapa 1999). Também foram obtidos os dados pluviométricos do período de estudo (janeiro/2004 a junho/2005) na Estação Meteorológica de Quarai, para inferir sobre possíveis relações entre a variação da cobertura vegetal ao longo do tempo e o padrão das chuvas da região. Para tanto, também foram obtidos os dados diários de precipitação do período de janeiro a maio/2005 junto a Ascar/Emater de São
Francisco de Assis, RS, com o intuito de verificar a ocorrência de chuvas torrenciais. O clima da região corresponde ao tipo Cfa, segundo a classificação de Köppen, com precipitação média anual de $1.400 \mathrm{~mm}$ e temperatura média que variam de $14,3{ }^{\circ} \mathrm{C}$ no inverno até $26,3{ }^{\circ} \mathrm{C}$ no verão (Nimer 1979).

A determinação da composição florística em toda a área de estudo iniciou em fevereiro/2004 e se estendeu até junho/2005. As subáreas foram percorridas na íntegra e houve a coleta de material botânico em estágio reprodutivo. O material coletado foi herborizado e incorporado ao acervo do Herbário HVAT (Herbário do Vale do Taquari) do Museu de Ciências Naturais do Centro Universitário Univates. As famílias foram consideradas de acordo com a APG-II (2003).

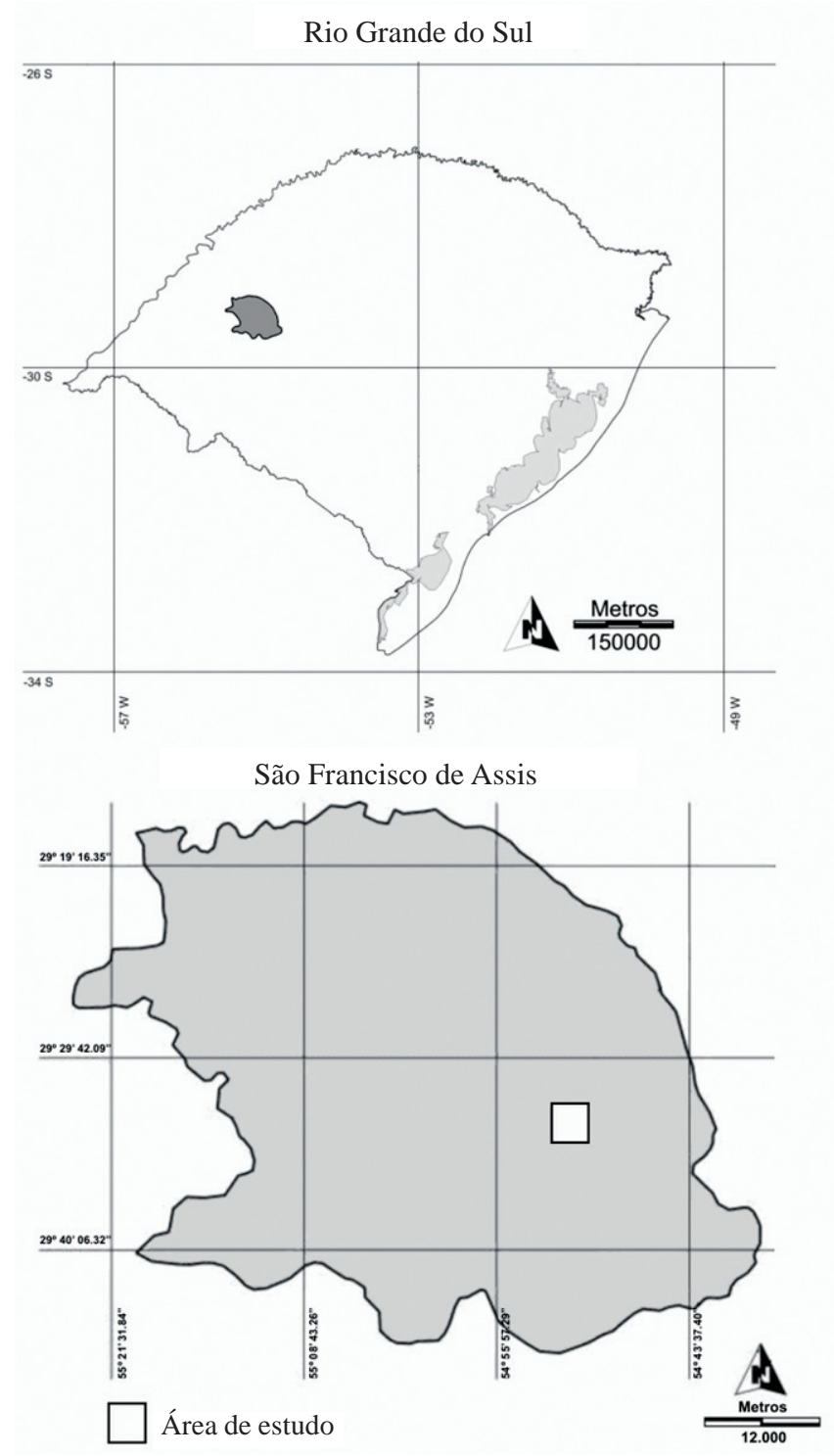

Figura 1. Localização do município de São Francisco de Assis, RS, Brasil e área de estudo (Elaboração: Rafael Eckhardt, Museu de Ciências Naturais da Univates 2005). 
Para a coleta dos dados fitossociológicos, foram demarcadas 35 unidades amostrais (UA) permanentes em cada uma das subáreas, distribuídas sistematicamente a cada $28 \mathrm{~m}$, em cinco linhas. Cada UA correspondia a um quadro com $50 \mathrm{~cm}$ de lado, subdivido em unidades menores de $4 \mathrm{~cm}^{2}$ (Matteuci \& Colma 1982) para estimativa do valor de cobertura. As UA foram mapeadas com o uso de GPS e marcadas com estacas numeradas, dispostas em dois vértices oblíquos, para permitir levantamentos em períodos subseqüentes.

A variação da cobertura vegetal e o avanço da arenização, através do aumento do solo exposto, foram avaliados a partir de três levantamentos fitossociológicos em ambas as subáreas: setembro/2004, janeiro/2005 e maio/2005 nas UA permanentes, culminando com um período de 10 meses de análise. Em cada UA, foi registrada a cobertura das espécies vegetais vasculares, do solo exposto e do mantilho, por meio da estimativa da superfície ocupada pela projeção horizontal da parte aérea de cada variável (Mueller-Dombois \& Ellenberg 1974). A partir dos dados, foram calculados os descritores de cobertura, frequiência e índice de valor de importância (IVI) para os três levantamentos. Da mesma forma, a riqueza de espécies e a diversidade de Shannon (H'), com base no logaritmo natural (nats) (Pielou 1969; Whittaker 1972), foram estimadas para cada uma das unidades amostrais e posteriormente comparadas suas variações conforme os fatores temporal e espacial.

As diferenças apresentadas pela cobertura das espécies, do solo exposto e do mantilho dentro das duas subáreas foram avaliadas considerando o tempo (período do levantamento - gradiente temporal) e a distância da encosta (gradiente espacial) como fatores de variação. As espécies foram agrupadas de acordo com sua forma biológica e constituíram gramíneas reptantes, gramíneas eretas, herbáceas, arbustos, subarbustos e suculentas, de acordo com as descrições das floras do Rio Grande do Sul e Santa Catarina. Assim, os valores de cobertura das espécies de uma mesma UA, cuja forma biológica era idêntica, foram somados conforme o grupo. As variáveis solo exposto e mantilho foram mantidas individualizadas. Da mesma forma, a riqueza e a diversidade de espécies (índice de Shannon), estimadas para cada UA, também foram inseridas nas análises de variação temporal e espacial. Ao todo, foram 10 variáveis avaliadas de acordo com os fatores tempo e distância da encosta. Para o tempo, cada período de levantamento foi considerado como um tratamento. Para a distância da encosta, as UA foram agrupadas de acordo com a sua posição espacial em relação à encosta: próximo (1-30 m), intermediário (31-60 m) e distante $(61-100 \mathrm{~m})$ e os números de UAs foram, respectivamente, 36,33 e 36.
Todas as análises de variância, comparando os tratamentos dentro dos fatores tempo e distância da encosta, foram realizadas por meio de testes de aleatorização (Pillar \& Orlóci 1996; Manly 1997), utilizando-se a distância euclidiana como medida de dissimilaridade entre grupos. Nos testes de aleatorização, foram geradas 1.000 iterações de auto-reamostragem e a probabilidade mínima adotada para considerar diferenças significativas entre os grupos avaliados foi $P \leq 0,05$. Tais análises foram geradas no aplicativo Multiv versão 2.3.9 (Pillar 2004).

Como as duas subáreas apresentavam situações distintas que não puderam ser testadas, comparações quanto à presença ou não de cobertura na encosta do cerro, assim como a influência das dinâmicas pluviométricas mensais e das características pedológicas das subáreas, foram discutidas num contexto geral de relações que podem interferir na dinâmica vegetacional de campos com arenização.

\section{Resultados e discussão}

Fatores abióticos: solo e pluviosidade - Os campos das áreas suscetíveis ao processo de arenização apresentam aspectos distintos do restante da Campanha. O solo profundo, arenoso e permeável favorece o crescimento de uma vegetação diversificada, pertencente a várias famílias botânicas, com um contingente de espécies dotadas de adaptações morfológicas às condições locais (Marchiori 1995).

O solo das subáreas 1 e 2 é do tipo Latossolo, apresentando textura que varia entre arenosa e argilosa (Tab. 1). Pertencem à classe textural 4 , que compreende os solos com quantidade menor ou igual a $20 \%$ de argila (Embrapa 1999), com tendência a erosão. Esses solos de textura arenosa são associados majoritariamente ao material de origem da Formação Botucatu e apresentam carências em $\mathrm{P}$ (fósforo) e K (potássio) e excedente em $\mathrm{Al}$ (alumínio), responsável, em parte, pelo $\mathrm{pH}$ ácido que varia de 4,5 a 6 (Bassi \& Verdum 2006).

Ao considerar os padrões para agricultura (SBCS 2004), o solo da subárea 1 apresentou baixo valor de MO (matéria orgânica); pequena quantidade de $\mathrm{P}$ (fósforo), $\mathrm{K}$ (potássio) e $\mathrm{Mg}$ (magnésio); grande quantidade de $\mathrm{H}$ (hidrogênio); alta saturação de $\mathrm{Al}$ (alumínio) $(44,4 \%)$ em comparação com outros elementos $(\mathrm{Ca}$ - cálcio, $\mathrm{Mg}$ - magnésio, $\mathrm{Na}$ - sódio, $\mathrm{S}$ enxofre, $\mathrm{Cu}$ - cobre, $\mathrm{Zn}$ - zinco, B - boro e $\mathrm{Mn}$ manganês) contidos na solução do solo; baixos índices de CTC e de saturação de bases (Tab. 1). Já o solo da subárea 2 apresentou alto valor de K, concentração de $\mathrm{Mg}$ dentro dos padrões favoráveis ao crescimento das plantas e baixa concentração de P. A saturação de bases, 
Tabela 1. Resultados obtidos nas análises do solo das subáreas 1 e 2 com as quantidades adequadas para solos pertencentes à classe textural 4 , de acordo com a Sociedade Brasileira de Ciência do Solo - SBCS (2004), São Francisco de Assis, RS, Brasil.

\begin{tabular}{|c|c|c|c|}
\hline Elementos/Unidades & Subárea 1 & Subárea 2 & $\begin{array}{c}\text { Características químicas adequadas } \\
\text { (SBCS 2004) }\end{array}$ \\
\hline P (fósforo) (mg.dm³) & 10,3 & 3,2 & $14-42$ \\
\hline $\mathrm{K}$ (potássio) $\left(\mathrm{mg} \cdot \mathrm{dm}^{-3}\right)$ & 27,0 & 62,6 & ${ }^{*}$ CTC abaixo de 5: 30-45 \\
\hline$\left(\mathrm{CTC}=\mathrm{cmol}_{\mathrm{c}} \cdot \mathrm{dm}^{-3}\right)$ & $(\mathrm{CTC}=0,91$ e 2,7$)$ & $(\mathrm{CTC}=3,0$ e 12,5$)$ & *CTC de 5 a $15: 40-60$ \\
\hline $\mathrm{Cu}($ cobre $)\left(\mathrm{mg} \cdot \mathrm{dm}^{-3}\right)$ & 0,162 & 0,05 & 0,2 a 0,4 \\
\hline Zn (zinco) $\left(\mathrm{mg} \cdot \mathrm{dm}^{-3}\right)$ & 1,06 & 0,26 & 0,2 a 0,5 \\
\hline B (boro) $\left(\mathrm{mg} \cdot \mathrm{dm}^{-3}\right)$ & 0,57 & 0,41 & 0,1 a 0,4 \\
\hline $\mathrm{Ca}$ (cálcio) $\left(\mathrm{cmol}_{\mathrm{c}} \cdot \mathrm{dm}^{-3}\right)$ & 0,3 & 1,6 & 2,1 a 4 \\
\hline $\mathrm{Mg}$ (magnésio) $\left(\mathrm{cmol}_{\mathrm{c}} \cdot \mathrm{dm}^{-3}\right)$ & 0,2 & 1,0 & 0,6 a 1 \\
\hline $\mathrm{Al}$ (alumínio) $\left(\mathrm{cmol}_{\mathrm{c}} \cdot \mathrm{dm}^{-3}\right)$ & 0,4 & 0,2 & 0,3 a 0,6 \\
\hline $\mathrm{CTC}_{\mathrm{pH} 7}$ & 2,7 & 12,5 & 5,1 a 15 \\
\hline Matéria orgânica (\%) & 0,8 & 0,7 & 2,6 a 5 \\
\hline $\mathrm{pH}$ & 5,6 & 5,3 & 5,5 a 6,5 \\
\hline
\end{tabular}

embora baixa, foi maior que a saturação de $\mathrm{Al}$ nesta subárea (Tab. 1).

As características do solo da subárea 1 podem ser relacionadas com pouca resistência a processos erosivos eólicos ou hídricos e baixa fertilidade, dificultando o desenvolvimento das plantas pela presença de nutrientes essenciais em níveis baixos ou insuficientes e pela dificuldade de armazenamento de água, provocando consideráveis déficits hídricos, mesmo em curtos períodos de estiagem (Azevedo \& Kaminski 1995). O substrato arenoso pouco consolidado, a baixa concentração de nutrientes e de matéria orgânica, da CTC e saturação de bases limitam o desenvolvimento da vegetação local, tornando essas comunidades campestres ainda mais sensíveis aos efeitos de lixiviação e do sobrepastoreio. Este, por sua vez, modifica a estrutura vertical e espacial dos campos nativos pela alteração das espécies dominantes e maior presença de áreas desprovidas de vegetação, expostas à ação das chuvas (Marchiori 1995). Além disso, essa subárea apresentou alta saturação de $\mathrm{Al}$, que aprisiona as bases, provoca queda na atividade biológica e exerce ação tóxica direta no desenvolvimento das raízes de algumas espécies vegetais (Basso \& Verdum 2006). A saturação de Al, associada à grande quantidade de $\mathrm{H}$, exerce ação antagônica na absorção dos cátions básicos, cuja intensidade na capacidade de retenção reforça o caráter ácido dos solos (Basso \& Verdum 2006). Portanto, a subárea 1 apresentou evidências de estar em processo avançado de arenização, o que resulta na degradação ambiental e na perda das características ecossistêmicas originais.

Na subárea 2, os resultados indicaram melhores condições ambientais. As características físico-químicas associadas à maior disponibilidade de $\mathrm{K} \mathrm{e} \mathrm{Mg}$ e a baixa saturação de Al favorecem o crescimento e o desenvolvimento da vegetação (Tab. 1). Apesar disso, o baixo teor de matéria orgânica no solo também indicou pouca retenção de material morto junto ao solo, que pode ser associado ao tipo de substrato e ao processo de arenização.

Estes solos são considerados pouco resilientes, ou seja, têm baixa capacidade de resistir ao processo de degradação e/ou de retornar às condições de pré-perturbação, tendo em vista que: apresentam baixa capacidade de resposta às práticas de manejo com incremento da fração orgânica e de nutrientes; sua textura arenosa e o baixo grau de agregação agem como fatores impeditivos aos incrementos, ao mesmo tempo que, uma vez expostos, acentuam os processos de degradação (A.P.M. Rovedder, comunicação pessoal). Uma vez iniciado o processo de arenização, devido ao intenso transporte de sedimentos por erosão hídrica e eólica, ocorre soterramento e efeito abrasivo sobre a vegetação que estiver próxima (A.P.M. Rovedder, comunicação pessoal).

Os dados pluviométricos indicaram a ocorrência de períodos de intensa redução na quantidade de chuvas, seguidos por meses chuvosos, com grande quantidade de chuvas, por vezes concentrada num único dia (p. ex., em 31/março/2005, a precipitação foi de $108 \mathrm{~mm}$ ), o que caracteriza chuvas torrenciais. Ao longo do período de estudo, houve meses com picos de precipitação elevada, seguidos de redução na quantidade de chuvas (Fig. 2). Este comportamento pluviométrico normalmente aumenta a probabilidade de efeitos erosivos, conforme foi observado durante no mês de janeiro/2005, período de reduzida precipitação, quando o pisoteio do gado sobre a vegetação e o solo secos provocava a remoção de ambos. As chuvas torrenciais posteriores a esse período provocaram a movimentação do solo e da cobertura vegetal, causando o aumento significativo das manchas de areia, como observado pela maior cobertura de solo exposto no levantamento de maio. As chuvas torrenciais 


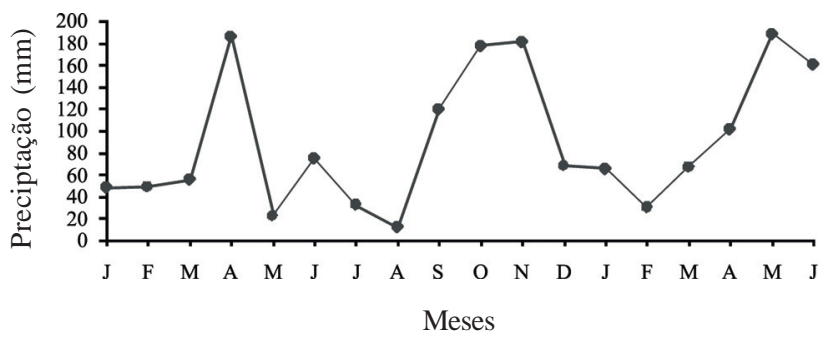

Figura 2. Variação mensal da quantidade de chuvas $(\mathrm{mm})$ de janeiro/2004 a junho/2005 (Fonte: Estação Meteorológica de Quarai, RS, Brasil).

e o mau uso do solo (p. ex., sobrepastoreio ou aragem do solo para cultivos) são responsáveis diretos pelo agravamento do processo erosivo (Medeiros et al. 1995).

Florística e fitossociologia - A vegetação da Campanha é composta por espécies com densa pilosidade, folhas coriáceas, formas e posições foliares que reduzem a superfície exposta à luz solar, presença de óleos, essências e órgãos subterrâneos espessos, entre outros, que atuam como estratégias de adaptação a diferentes condições de vida: crescimento em lugar desabrigado, terreno quente e pobre em água e precipitação escassa (Lindman 1906). Os caracteres expostos, tomados no seu conjunto, definem a vegetação da Campanha, diferenciando-a de qualquer outra comunidade vegetal (Rambo 1956). Tais adaptações poderiam ser supérfluas nas condições climáticas atuais, porém testemunham a ocorrência de fases xerotérmicas do Quaternário dessa região americana e atestam um caráter relictual a esses elementos da flora (Marchiori 1995). Essas mesmas adaptações são importantes em ecossistemas campestres submetidos a perturbações periódicas (queimadas, déficits hídricos) ou contínuas (pastejo), comuns na região do Pampa (Overbeck et al. 2007).

A flora das duas subáreas compreendeu 102 espécies e 79 gêneros pertencentes a 25 famílias (Tab. 2). Desse total, 61 espécies e 21 famílias são comuns às duas subáreas. As famílias com maior riqueza foram: Poaceae (29 espécies), Asteraceae (18 espécies), Myrtaceae (seis espécies), Caryophyllaceae (cinco espécies), Fabaceae, Oxalidaceae e Rubiaceae (quatro espécies). Na subárea 1 foram listadas 77 espécies pertencentes a 22 famílias e na subárea 2 foram 86 espécies e 24 famílias. Com exceção de Asteraceae, todas as famílias que ocorreram nas duas subáreas apresentaram maior número de espécies na subárea 2. A presença de mirtáceas chama a atenção, pois normalmente esta não é uma família típica de ecossistemas campestres (Boldrini 1997).

Na subárea 1, as espécies Paspalum stellatum e P. nicorae, associadas ao solo exposto e ao mantilho, apresentaram as maiores coberturas relativas e IVIs durante os três levantamentos (Tab. 3). Na subárea 2 (Tab. 4), as variáveis com maior cobertura relativa e IVI foram as mesmas, no entanto a proporção de solo exposto na 1 foi consideravelmente maior que na 2 , especialmente no último levantamento, apesar dos dominantes $P$. nicorae e $P$. stellatum terem participação similar.

$\mathrm{O}$ aumento de solo exposto na área 1, com conseqüente redução da cobertura da maioria das espécies, ocorreu ao longo do período de estudo (set./2004: 43,38\%; jan./2005: 49,8\%; maio/2005: 70\%), embora o último tenha sido acentuado, corroborando com a hipótese do efeito do padrão da precipitação daquele período em acentuar o processo. O levantamento de janeiro coincidiu com um período de estiagem que se prolongou até março. Em maio, quando foi realizado o terceiro levantamento, não havia mais estiagem, entretanto suas consequiências refletiram na cobertura vegetal reduzida e no aumento do solo exposto.

Os descritores fitossociológicos indicaram um padrão típico de comunidades campestres ricas em espécies, onde poucas espécies são abundantes, contrapondo com um elevado número de espécies com baixo desempenho na comunidade (Boldrini et al. 1998, Overbeck et al. 2006). Ao analisar as espécies dominantes, houve predominância de espécies prostradas nas duas subáreas, provavelmente favorecidas pela ação do pisoteio do gado, em detrimento de outras herbáceas que não toleram tal perturbação contínua, o que dá ao campo a fisionomia característica de campo limpo (Lindman 1906; Rambo 1956). Esses dados confirmaram que o pastoreio beneficia espécies rizomatosas e estoloníferas, inibindo plantas cespitosas e rosuladas, corroborando dados de avaliação das modificações ocorridas em uma área de campo natural com a exclusão de animais (Boldrini \& Eggers 1996). A ocorrência de indivíduos isolados de Andropogon lateralis, A. selloanus e das Aristida spp. nas duas subáreas, espécies cespitosas comuns nos campos sulinos, e ausência destas nos levantamentos fitossociológicos reforçam essa constatação. No caso de A. lateralis, sabe-se que o pisoteio intensivo pelo gado provoca a diminuição de sua vitalidade, contribuindo para o predomínio de gramíneas rizomatosas (Smith et al. 1982).

Padrões de dinâmica temporal e espacial - Os padrões de variação da riqueza e diversidade de espécies, bem como do percentual de cobertura das formas biológicas avaliadas (gramíneas reptantes e eretas, herbáceas, subarbustos, arbustos e suculentas), do mantilho e do solo exposto foram analisados conforme os fatores tempo e distância da encosta (Tab. 5-6).

A riqueza e a diversidade de espécies apresentaram redução na subárea 1 ao longo do tempo, sendo maiores 
Tabela 2. Lista das famílias e espécies presentes em campo nativo com os respectivos testemunhos, ocorrência nas subáreas 1 e 2 e forma de vida. São Francisco de Assis, RS, Brasil, fevereiro/2004 a junho/2005. (0 - sem registro; X* - não aparece no levantamento fitossociológico da referida subárea; Gram. ereta = gramínea ereta; Gram. rep. = gramínea reptante).

\begin{tabular}{|c|c|c|c|c|}
\hline \multirow[t]{2}{*}{ Família/Espécie } & \multirow[t]{2}{*}{ Testemunho } & \multicolumn{2}{|c|}{ Ocorrências subáreas } & \multirow[t]{2}{*}{ Forma de vida } \\
\hline & & 1 & 2 & \\
\hline \multicolumn{5}{|l|}{ ACANTHACEAE } \\
\hline Justicia axillaris (Nees.) Lindau & HVAT 1444 & $\mathrm{X}^{*}$ & & Subarbusto \\
\hline Ruellia bulbifera Lindau & HVAT 1566 & $\mathrm{X}$ & $\mathrm{X}$ & Herbácea \\
\hline Stenandrium dulce (Cav.) Nees & HVAT 1721 & $\mathrm{X}$ & $X^{*}$ & Herbácea \\
\hline \multicolumn{5}{|l|}{ AIZOACEAE } \\
\hline Mollugo verticillata $\mathrm{L}$. & HVAT 1372 & $\mathrm{X}$ & $\mathrm{X}$ & Herbácea \\
\hline \multicolumn{5}{|l|}{ ALLIACEAE } \\
\hline Nothoscordum inodorum (Aiton) Asch. \& Graebn & HVAT 1559 & $\mathrm{X}$ & $X^{*}$ & Herbácea \\
\hline \multicolumn{5}{|l|}{ AMARANTHACEAE } \\
\hline Froelichia tomentosa (Mart.) Moq. & HVAT 1404 & $\mathrm{X}$ & $\mathrm{X}$ & Herbácea \\
\hline Gomphrena graminea Moq. & HVAT 1697 & $\mathrm{X}^{*}$ & & Herbácea \\
\hline Pfaffia tuberosa (Spreng.) Hicken & HVAT 1708 & $X^{*}$ & & Herbácea \\
\hline \multicolumn{5}{|l|}{ APIACEAE } \\
\hline Apium leptophyllum (Pers.) F. Müell. ex Benth. & HVAT 1594 & $\mathrm{X}$ & $\mathrm{X}$ & Herbácea \\
\hline \multicolumn{5}{|l|}{ APOCYNACEAE } \\
\hline Asclepias campestris Vell. & HVAT 1561 & $\mathrm{X}$ & $\mathrm{X}$ & Subarbusto \\
\hline \multicolumn{5}{|l|}{ ASTERACEAE } \\
\hline Acanthospermum australe (Loefl.) Kuntze & HVAT 1443 & $\mathrm{X}^{*}$ & $\mathrm{X}^{*}$ & Herbácea \\
\hline Aspilia montevidensis (Spreng.) Kuntz & HVAT 1696 & $\mathrm{X}^{*}$ & & Subarbusto \\
\hline Chaptalia nutans (L.) Pol. & HVAT 1722 & $\mathrm{X}^{*}$ & & Subarbusto \\
\hline Conyza bonariensis var. microcephala (Cabr.) Cabrera & HVAT 1380 & $X^{*}$ & $\mathrm{X}$ & Subarbusto \\
\hline Elephantopus mollis Kunth & HVAT 1385 & & $\mathrm{X}$ & Subarbusto \\
\hline Eupatorium subhastatum Hooker et Arnott & HVAT 1449 & $\mathrm{X}$ & & Subarbusto \\
\hline Facelis retusa (Lam.) Sch. - Bip. & HVAT 1593 & $\mathrm{X}$ & $\mathrm{X}$ & Herbácea \\
\hline Gamochaeta americana (Mill) Weddell & HVAT 1625 & $\mathrm{X}$ & $\mathrm{X}$ & Herbácea \\
\hline G. falcata (Lam.) Cabrera & HVAT 1558 & $\mathrm{X}$ & $\mathrm{X}$ & Herbácea \\
\hline Noticastrum gnaphalioides (Baker) Cuatrecasas & HVAT 1445 & & $X^{*}$ & Subarbusto \\
\hline Senecio cisplatinus Cabr. & HVAT 1536 & $\mathrm{X}$ & & Subarbusto \\
\hline S. riograndensis Matzenbacher & HVAT 1557 & & $\mathrm{X}$ & Subarbusto \\
\hline Soliva pterosperma (Juss.) Less. & HVAT 1564 & & $\mathrm{X}$ & Herbácea \\
\hline Stenachaenium riedelii Baker & - & $X^{*}$ & & Subarbusto \\
\hline Vernonia brevifolia Less. & HVAT 1419 & $\mathrm{X}$ & & Subarbusto \\
\hline V. macrocephala Less. & HVAT 1418 & $\mathrm{X}$ & $\mathrm{X}$ & Subarbusto \\
\hline V. nudiflora Less. & HVAT 1411 & $X^{*}$ & $\mathrm{X}$ & Subarbusto \\
\hline Espécie não identificada & - & $\mathrm{X}$ & $\mathrm{X}$ & Herbácea \\
\hline \multicolumn{5}{|l|}{ CACTACEAE } \\
\hline Cereus hildmannianus K. Schuman & HVAT 1705 & & $X^{*}$ & Suculenta \\
\hline Echinopsis oxygona (Link.) Zucc. & HVAT 1693 & $\mathrm{X}^{*}$ & & Suculenta \\
\hline Parodia ottonis (Lehmann) N.P. Taylor & HVAT 1595 & $\mathrm{X}$ & $\mathrm{X}$ & Suculenta \\
\hline \multicolumn{5}{|l|}{ CARYOPHYLLACEAE } \\
\hline Cardionema ramosissima (Weinm.) A. Nelson \& J.F. Macbr. & HVAT 1366 & $\mathrm{X}$ & $\mathrm{X}$ & Herbácea \\
\hline Cerastium commersonianum DC. & HVAT 1560 & $\mathrm{X}$ & $\mathrm{X}$ & Herbácea \\
\hline Paronychia brasiliana DC. & HVAT 1401 & $\mathrm{X}$ & $\mathrm{X}^{*}$ & Herbácea \\
\hline Polycarpon tetraphyllum (L.) L. & HVAT 1637 & & $\mathrm{X}$ & Herbácea \\
\hline Stellaria media (L.) Vill. & HVAT 1533 & & $\mathrm{X}^{*}$ & Herbácea \\
\hline \multicolumn{5}{|l|}{ CISTACEAE } \\
\hline Helianthemum brasiliense (Lam.) Pers. & HVAT 1535 & $\mathrm{X}$ & $\mathrm{X}$ & Herbácea \\
\hline \multicolumn{5}{|l|}{ COMMELINACEAE } \\
\hline Commelina platyphylla Klotzsch var. bolansai & HVAT 1628 & & $\mathrm{X}$ & Herbácea \\
\hline Commelina erecta $\mathrm{L}$. & HVAT 1630 & & $X^{*}$ & Herbácea \\
\hline \multicolumn{5}{|l|}{ CONVOLVULACEAE } \\
\hline Dichondra sericea Swartz & - & & $\mathrm{X}$ & Herbácea \\
\hline Evolvulus sericeus Swartz & HVAT 1388 & $\mathrm{X}$ & $\mathrm{X}$ & Herbácea \\
\hline \multicolumn{5}{|l|}{ CYPERACEAE } \\
\hline Bulbostylis capillaris var. elatior (Griseb.) Osten & HVAT 1375 & $\mathrm{X}$ & $\mathrm{X}$ & Herbácea \\
\hline Cyperus aggregatus (Willd.) Endl. & HVAT 1410 & $\mathrm{X}$ & $\mathrm{X}$ & Herbácea \\
\hline Kyllinga vaginata Lam. & HVAT 1422 & $\mathrm{X}$ & $\mathrm{X}$ & Herbácea \\
\hline
\end{tabular}


Tabela 2 (continuação)

\begin{tabular}{|c|c|c|c|c|}
\hline \multirow[t]{2}{*}{ Família/Espécie } & \multirow[t]{2}{*}{ Testemunho } & \multicolumn{2}{|c|}{ Ocorrências subáreas } & \multirow[t]{2}{*}{ Forma de vida } \\
\hline & & 1 & 2 & \\
\hline \multicolumn{5}{|l|}{ EUPHORBIACEAE } \\
\hline Euphorbia papillosa A. St.-Hil. & HVAT 1455 & $\mathrm{X}$ & $\mathrm{X}$ & Herbácea \\
\hline Jatropha isabellii Muell. Arg. & HVAT 1390 & $\mathrm{X}$ & $\mathrm{X}$ & Herbácea \\
\hline \multicolumn{5}{|l|}{ FABACEAE } \\
\hline Chamaecrista flexuosa (L.) E. Greene var. flexuosa & HVAT 1398 & $\mathrm{X}$ & $\mathrm{X}$ & Subarbusto \\
\hline Desmodium incanum DC. & HVAT 1452 & & $\mathrm{X}$ & Subarbusto \\
\hline Stylosanthes montevidensis Vogel & HVAT 1402 & $\mathrm{X}$ & $\mathrm{X}$ & Subarbusto \\
\hline Zornia reticulata $\mathrm{Sm}$. & HVAT 1413 & $\mathrm{X}$ & $\mathrm{X}$ & Subarbusto \\
\hline \multicolumn{5}{|l|}{ IRIDACEAE } \\
\hline Sisyrinchium micranthum Cav. & HVAT 1596 & & $\mathrm{X}$ & Herbácea \\
\hline \multicolumn{5}{|l|}{ LAMIACEAE } \\
\hline Salvia brevipes Benth. & HVAT 1391 & $\mathrm{X}^{*}$ & $\mathrm{X}^{*}$ & Subarbusto \\
\hline Marsypianthes hassleri Briq. & HVAT 1470 & $\mathrm{X}$ & & Subarbusto \\
\hline \multicolumn{5}{|l|}{ MALVACEAE } \\
\hline Ayenia mansfeldiana (Herter) Herter \& Cristóbal & HVAT 1635 & $\mathrm{X}$ & $\mathrm{X}$ & Herbácea \\
\hline Walteria douradinha A. St.-Hil. & HVAT 1433 & $\mathrm{X}$ & $\mathrm{X}$ & Subarbusto \\
\hline \multicolumn{5}{|l|}{ MYRTACEAE } \\
\hline Campomanesia aurea O. Berg. & HVAT 1647 & $\mathrm{X}$ & $\mathrm{X}$ & Arbusto \\
\hline Eugenia arenosa Mattos & HVAT 1694 & $\mathrm{X}$ & $\mathrm{X}$ & Arbusto \\
\hline E. pitanga $(\mathrm{O}$. Berg. $)$ Nied. & HVAT 1490 & $\mathrm{X}^{*}$ & $\mathrm{X}$ & Arbusto \\
\hline E. plurisepala Barb. Rodr. ex Chod. \& Hassl. & HVAT 1632 & $\mathrm{X}^{*}$ & $\mathrm{X}$ & Arbusto \\
\hline Myrcia verticillaris $\mathrm{O}$. Berg. & HVAT 1474 & & $X^{*}$ & Arbusto \\
\hline Psidium luridum (Spreng.) Burret & HVAT 645 & & $\mathrm{X}$ & Arbusto \\
\hline \multicolumn{5}{|l|}{ OXALIDACEAE } \\
\hline Oxalis articulata Savigny & HVAT 1476 & & $\mathrm{X}$ & Herbácea \\
\hline O. eriocarpa DC. & HVAT 1532 & & $\mathrm{X}$ & Herbácea \\
\hline O. hispidula Zucc. & HVAT 1529 & & $\mathrm{X}$ & Herbácea \\
\hline O. perdicaria (Molina) Bertero & HVAT 1475 & $\mathrm{X}$ & $\mathrm{X}$ & Herbácea \\
\hline \multicolumn{5}{|l|}{ PLANTAGINACEAE } \\
\hline Plantago tomentosa Lam. & HVAT 1570 & & $\mathrm{X}$ & Herbácea \\
\hline \multicolumn{5}{|l|}{ POACEAE } \\
\hline Andropogon lateralis Nees & HVAT 1442 & $X^{*}$ & $X^{*}$ & Gram. ereta \\
\hline A. selloanus (Hackel) Hackel & HVAT 1396 & $X^{*}$ & $X^{*}$ & Gram. ereta \\
\hline Aristida circinalis Lindm. & HVAT 1435 & $\mathrm{X}^{*}$ & & Gram. ereta \\
\hline A. condylifolia Caro & HVAT 1477 & $X^{*}$ & & Gram. ereta \\
\hline Axonopus affinis Chase & HVAT 1639 & $\mathrm{X}$ & $\mathrm{X}$ & Gram.rep. \\
\hline A. argentinus Parodi & HVAT 1652 & $\mathrm{X}$ & $\mathrm{X}$ & Gram. ereta \\
\hline A. fissifolius (Raddi) Kuhlm. & HVAT 1695 & $\mathrm{X}$ & $\mathrm{X}$ & Gram. ereta \\
\hline Briza subaristata var interrupta (Hack.) Roseng., Arril. \& Izag. & HVAT 1599 & & $\mathrm{X}^{*}$ & Gram. ereta \\
\hline Dichanthelium sabulorum (Lam.) Gould \& C.A. Clark. & HVAT 1389 & $\mathrm{X}$ & $\mathrm{X}$ & Gram. ereta \\
\hline Digitaria ciliaris (Retz.) Koeler & HVAT 1471 & $X^{*}$ & $\mathrm{X}^{*}$ & Gram. ereta \\
\hline D. insularis (L.) Fedde & HVAT 1393 & $\mathrm{X}^{*}$ & $\mathrm{X}$ & Gram. ereta \\
\hline Eleusine tristachya (Lam.) Lam. & HVAT 1638 & & $\mathrm{X}$ & Gram. ereta \\
\hline Eragrostis cf. bahiensis Schrad. & HVAT 1473 & $X^{*}$ & & Gram. ereta \\
\hline E. lugens Nees & HVAT 1453 & $\mathrm{X}$ & $\mathrm{X}$ & Gram. ereta \\
\hline E. neesii Trin. & HVAT 1373 & $\mathrm{X}$ & $\mathrm{X}$ & Gram. ereta \\
\hline Eustachys retusa (Lag.) Kunth & HVAT 1371 & $\mathrm{X}$ & $\mathrm{X}$ & Gram. ereta \\
\hline Gymnopogon spicatus (Spreng.) Kuntze & HVAT 1374 & $\mathrm{X}$ & $\mathrm{X}$ & Gram. ereta \\
\hline Microchloa indica (L.F.) P. Beauv. & HVAT 1562 & & $\mathrm{X}$ & Gram. ereta \\
\hline Paspalum nicorae Parodi & HVAT 1399 & $\mathrm{X}$ & $\mathrm{X}$ & Gram. rep. \\
\hline P. notatum $\mathrm{Fl}$. & HVAT 1368 & $\mathrm{X}$ & $\mathrm{X}$ & Gram. rep. \\
\hline P. polyphyllum Nees & HVAT 1436 & $\mathrm{X}$ & $\mathrm{X}$ & Gram. ereta \\
\hline P. stellatum $\mathrm{H}$. \& B. ex Fl. & HVAT 1450 & $\mathrm{X}$ & $\mathrm{X}$ & Gram. rep. \\
\hline Piptochaetium montevidense (Spreng.) Parodi & HVAT 1597 & & $\mathrm{X}$ & Gram. ereta \\
\hline Melinis repens (Willd.) Zizka & HVAT 1377 & $\mathrm{X}$ & $\mathrm{X}$ & Gram. ereta \\
\hline Schizachyrium spicatum (Spreng.) Herter & HVAT 1493 & $\mathrm{X}$ & $\mathrm{X}$ & Gram. ereta \\
\hline Setaria parviflora (Poir.) Kerguélen & HVAT 1376 & $\mathrm{X}$ & $\mathrm{X}$ & Gram. ereta \\
\hline Sporobolus indicus (L.) R. Br. var. indicus & HVAT 1466 & & $\mathrm{X}$ & Gram. ereta \\
\hline Steinchisma hians (Elliott) Nash & HVAT 1406 & $X^{*}$ & $\mathrm{X}$ & Gram. ereta \\
\hline Vulpia australis (Ness ex Steud.) C.H. Blom & HVAT 1569 & & $\mathrm{X}$ & Gram. ereta \\
\hline
\end{tabular}


Tabela 2 (continuação)

\begin{tabular}{|c|c|c|c|c|}
\hline \multirow[t]{2}{*}{ Família/Espécie } & \multirow[t]{2}{*}{ Testemunho } & \multicolumn{2}{|c|}{ Ocorrências subáreas } & \multirow[t]{2}{*}{ Forma de vida } \\
\hline & & 01 & 02 & \\
\hline \multicolumn{5}{|l|}{ PORTULACACEAE } \\
\hline Portulaca grandiflora Hook. & HVAT 1646 & $\mathrm{X}^{*}$ & & Herbácea \\
\hline Portulaca sp. & HVAT 1645 & $\mathrm{X}$ & & Herbácea \\
\hline \multicolumn{5}{|l|}{ RUBIACEAE } \\
\hline Borreria brachystemonoides Cham. \& Schltdl. & HVAT 1412 & $\mathrm{X}$ & $X$ & Herbácea \\
\hline B. verticillata (L.) G. Mey & HVAT 1538 & & $\mathrm{X}$ & Herbácea \\
\hline Mitracarpus megapotamicus (Spreng.) Kuntze & HVAT 1452 & $\mathrm{X}$ & $\mathrm{X}$ & Herbácea \\
\hline Richardia humistrata (Cham. \& Schltdl.) Steud. & HVAT 1403 & $\mathrm{X}$ & $\mathrm{X}$ & Herbácea \\
\hline \multicolumn{5}{|l|}{ SOLANACEAE } \\
\hline Solanum hasslerianum Chodat. & HVAT 1400 & $\mathrm{X}$ & $\mathrm{X}$ & Subarbusto \\
\hline
\end{tabular}

no primeiro levantamento. A diversidade reduziu significativamente do segundo para o terceiro levantamento, enquanto a riqueza diferiu somente do primeiro para o segundo, indicando que a menor diversidade foi decorrente de uma queda da eqüabilidade entre as espécies. Na subárea 2, tanto a riqueza quanto a diversidade foram maiores que na 1 , porém também houve um padrão de redução ao longo do tempo, embora menos acentuado. Estas avaliações sugerem maior estabilidade da comunidade da subárea 2 , uma vez que a resistência ao processo de arenização foi maior que a observada na 1. Comunidades mais diversas tendem à maior estabilidade frente a perturbações (Langevelde et al. 2003; Leps et al. 1982). Na avaliação espacial, a subárea 1 teve maior riqueza próximo da encosta do cerro, embora a diversidade não tenha variado. $\mathrm{Na}$ subárea 2, onde há maior cobertura arbórea na encosta do cerro, além de apresentar valores mais elevados, houve diferença significativa conforme a distância da encosta, indicando a importância da cobertura na retenção do escoamento superficial por ocasião das chuvas.

Tabela 3. Parâmetros fitossociológicos obtidos nos levantamentos de setembro/2004 (S/04), janeiro/2005 (J/05) e maio/2005 (M/05), apresentados em ordem decrescente da média do índice do valor de importância das variáveis amostradas na subárea 1, com IVI superior a 1, São Francisco de Assis, RS, Brasil.

\begin{tabular}{|c|c|c|c|c|c|c|c|c|c|}
\hline \multirow[t]{2}{*}{ Variável amostrada } & \multicolumn{3}{|c|}{$\begin{array}{c}\text { Cobertura relativa } \\
(\%)\end{array}$} & \multicolumn{3}{|c|}{$\begin{array}{c}\text { Frequiência relativa } \\
\qquad \%)\end{array}$} & \multicolumn{3}{|c|}{$\begin{array}{l}\text { Índice de valor de } \\
\text { importância }\end{array}$} \\
\hline & $\mathrm{S} / 04$ & $\mathrm{~J} / 05$ & $\mathrm{M} / 05$ & $\mathrm{~S} / 04$ & $\mathrm{~J} / 05$ & $\mathrm{M} / 05$ & $\mathrm{~S} / 04$ & $\mathrm{~J} / 05$ & $\mathrm{M} / 05$ \\
\hline Solo exposto & 43,38 & 49,80 & 70,00 & 8,10 & 9,64 & 10,64 & 25,74 & 29,72 & 40,32 \\
\hline Paspalum stellatum & 16,10 & 15,72 & 10,05 & 6,71 & 8,00 & 9,00 & 11,40 & 11,86 & 9,52 \\
\hline Mantilho & 16,17 & 7,06 & 5,30 & 8,10 & 9,37 & 10,64 & 12,13 & 8,21 & 7,97 \\
\hline Paspalum nicorae & 11,50 & 10,80 & 6,80 & 6,71 & 8,00 & 7,90 & 9,10 & 9,40 & 7,35 \\
\hline Bulbostylis capillaris & 0,48 & 1,04 & 0,40 & 5,55 & 7,44 & 5,20 & 3,01 & 4,24 & 2,80 \\
\hline Axonopus argentinus & 1,24 & 1,64 & 1,15 & 3,70 & 4,13 & 4,56 & 2,47 & 2,88 & 2,85 \\
\hline Gymnopogon spicatus & 1,03 & 1,63 & 0,92 & 3,01 & 4,41 & 4,25 & 2,02 & 3,02 & 2,58 \\
\hline Axonopus affinis & 0,55 & 0,74 & 0,60 & 3,01 & 4,13 & 4,56 & 1,78 & 2,43 & 2,58 \\
\hline Facelis retusa & 0,88 & 0 & 0,09 & 6,50 & 0 & 4,25 & 3,69 & 0 & 2,17 \\
\hline Evolvulus sericeus & 0,27 & 0,20 & 0,22 & 3,24 & 2,75 & 3,34 & 1,75 & 1,47 & 1,78 \\
\hline Cardionema ramosissimum & 0,30 & 0,72 & 0,23 & 2,80 & 2,75 & 2,74 & 1,55 & 1,73 & 1,48 \\
\hline Gamochaeta filaginea & 1,70 & 0 & 0 & 7,62 & 0 & 0 & 4,66 & 0 & 0 \\
\hline Eragrostis lugens & 0,52 & 0,60 & 0,22 & 1,85 & 2,20 & 2,43 & 1,18 & 1,40 & 1,32 \\
\hline Ayenia mansfeldiana & 0,20 & 0,46 & 0,22 & 1,85 & 2,48 & 2,13 & 1,02 & 1,47 & 1,17 \\
\hline Cyperus aggregatus & 0,17 & 0,23 & 0,20 & 2,08 & 2,20 & 2,13 & 1,12 & 1,21 & 1,16 \\
\hline Melinis repens & 0,51 & 0,36 & 0,20 & 2,08 & 1,93 & 1,82 & 1,29 & 1,14 & 1,01 \\
\hline Vernonia macrocephala & 0,32 & 0,94 & 0,25 & 1,62 & 1,93 & 1,82 & 0,97 & 1,43 & 1,03 \\
\hline Eragrostis neesii & 0,28 & 0,36 & 0,09 & 1,62 & 1,93 & 1,82 & 0,95 & 1,14 & 0,95 \\
\hline Froelichia tomentosa & 0,30 & 0,29 & 0,10 & 1,62 & 1,93 & 1,52 & 0,96 & 1,11 & 0,81 \\
\hline Dichanthelium sabulorum & 0,25 & 0,41 & 0,47 & 0,93 & 1,65 & 1,82 & 0,59 & 1,03 & 1,14 \\
\hline Borreria brachystemonoides & 0,12 & 0,32 & 0,06 & 1,62 & 2,20 & 0,91 & 0,87 & 1,26 & 0,48 \\
\hline $\begin{array}{l}\text { Demais espécies (36) com IVI } \\
\text { inferior a } 1 \text { (somatório) }\end{array}$ & 3,70 & 6,67 & 2,41 & 19,70 & 23,00 & 16,65 & 11,64 & 14,75 & 9,45 \\
\hline
\end{tabular}


Tabela 4. Parâmetros fitossociológicos obtidos nos levantamentos de setembro/2004 (S/04), janeiro/2005 (J/05) e maio/2005 (M/05), apresentados em ordem decrescente da média do índice do valor de importância das variáveis amostradas na subárea 2, com IVI superior a 1, São Francisco de Assis, RS, Brasil.

\begin{tabular}{|c|c|c|c|c|c|c|c|c|c|}
\hline \multirow[t]{2}{*}{ Variável amostrada } & \multicolumn{3}{|c|}{$\begin{array}{c}\text { Cobertura relativa } \\
(\%)\end{array}$} & \multicolumn{3}{|c|}{$\begin{array}{l}\text { Frequiência relativa } \\
\qquad(\%)\end{array}$} & \multicolumn{3}{|c|}{$\begin{array}{l}\text { Índice de valor de } \\
\text { importância }\end{array}$} \\
\hline & $\mathrm{S} / 04$ & $\mathrm{~J} / 05$ & $\mathrm{M} / 05$ & $\mathrm{~S} / 04$ & $\mathrm{~J} / 05$ & $\mathrm{M} / 05$ & $\mathrm{~S} / 04$ & $\mathrm{~J} / 05$ & $\mathrm{M} / 05$ \\
\hline Solo exposto & 19,97 & 23,85 & 27,99 & 5,20 & 6,35 & 6,00 & 12,58 & 15,10 & 16,99 \\
\hline Paspalum nicorae & 21,16 & 22,76 & 16,73 & 5,02 & 6,20 & 5,80 & 12,59 & 14,48 & 11,26 \\
\hline Paspalum stellatum & 13,26 & 13,68 & 11,60 & 3,70 & 4,54 & 4,23 & 8,48 & 9,11 & 7,91 \\
\hline Mantilho & 8,32 & 6,29 & 8,74 & 5,20 & 6,35 & 6,20 & 6,76 & 6,32 & 7,47 \\
\hline Paspalum notatum & 4,83 & 5,29 & 4,06 & 2,95 & 3,63 & 3,40 & 3,89 & 4,46 & 3,73 \\
\hline Soliva pterosperma & 4,20 & 0 & 10,90 & 3,54 & 0 & 4,41 & 3,87 & 0 & 7,65 \\
\hline Ayenia mansfeldiana & 1,20 & 2,57 & 1,10 & 4,13 & 5,62 & 4,20 & 2,66 & 4,09 & 2,65 \\
\hline Setaria parviflora & 2,98 & 3,17 & 1,95 & 2,80 & 3,45 & 3,20 & 2,89 & 3,31 & 2,57 \\
\hline Axonopus affinis & 1,60 & 1,94 & 1,90 & 2,95 & 3,63 & 3,40 & 2,27 & 2,78 & 2,65 \\
\hline Richardia humistrata & 0,85 & 1,63 & 0,40 & 4,13 & 5,62 & 2,65 & 2,49 & 3,62 & 1,52 \\
\hline Bulbostylis capillaris & 0,66 & 0,76 & 0,48 & 3,54 & 4,17 & 2,47 & 2,10 & 2,46 & 1,47 \\
\hline Facelis retusa & 1,41 & 0 & 1,04 & 4,13 & 0 & 5,30 & 2,77 & 0 & 3,17 \\
\hline Schizachyrium spicatum & 0,80 & 0,95 & 0,76 & 2,80 & 3,27 & 2,65 & 1,80 & 2,11 & 1,70 \\
\hline Evolvulus sericeus & 0,79 & 0,43 & 0,31 & 3,25 & 3,27 & 3,00 & 2,02 & 1,85 & 1,65 \\
\hline Kyllinga vaginata & 0,47 & 0,43 & 0,38 & 2,07 & 2,36 & 1,94 & 2,77 & 1,39 & 1,16 \\
\hline Vernonia macrocephala & 2,02 & 2,06 & 0,38 & 1,80 & 2,20 & 1,60 & 1,91 & 2,13 & 0,99 \\
\hline Cyperus aggregatus & 0,31 & 0,52 & 0,42 & 1,80 & 2,54 & 2,30 & 1,05 & 1,53 & 1,36 \\
\hline Sporobolus indicus & 1,04 & 0,75 & 0,70 & 1,47 & 1,81 & 1,76 & 0,25 & 1,28 & 1,23 \\
\hline Borreria brachystemonoides & 0,40 & 0,46 & 0,23 & 1,62 & 2,72 & 1,60 & 1,01 & 1,59 & 0,91 \\
\hline Eragrostis lugens & 0,43 & 0,50 & 0,44 & 1,62 & 2,00 & 1,94 & 1,02 & 1,25 & 1,19 \\
\hline Axonopus argentinus & 0,80 & 0,72 & 0,77 & 1,33 & 1,63 & 1,60 & 1,06 & 1,17 & 1,18 \\
\hline Gamochaeta americana & 0,46 & 0,33 & 0,31 & 1,92 & 2,00 & 1,76 & 1,19 & 1,16 & 1,03 \\
\hline Oxalis eriocarpa & 1,26 & 0,10 & 0,60 & 1,80 & 0,72 & 2,12 & 1,53 & 0,41 & 1,36 \\
\hline Cardionema ramosissimum & 0,70 & 0,67 & 0,40 & 1,47 & 1,81 & 1,23 & 1,08 & 1,24 & 0,81 \\
\hline Halimium brasiliense & 0,24 & 0,05 & 0,40 & 1,92 & 1,27 & 2,12 & 1,08 & 0,66 & 1,26 \\
\hline Piptochaetium montevidense & 0,31 & 0,28 & 0,30 & 1,33 & 1,63 & 1,76 & 0,82 & 0,95 & 1,03 \\
\hline Jatropha isabellii & 1,64 & 1,76 & 0,16 & 0,60 & 0,91 & 0,35 & 1,12 & 1,33 & 0,25 \\
\hline Stylosanthes montevidensis & 0,73 & 0,46 & 0,21 & 1,20 & 1,50 & 1,06 & 0,96 & 0,98 & 0,63 \\
\hline Campomanesia aurea & 1,05 & 1,36 & 1,36 & 0,30 & 0,54 & 0,53 & 0,67 & 0,95 & 0,94 \\
\hline Mitracarpus megapotamicus & 0,10 & 0,22 & 0,11 & 0,90 & 1,10 & 0,70 & 0,5 & 1,66 & 0,40 \\
\hline Eustachys retusa & 0,19 & 0,27 & 0,20 & 1,03 & 1,50 & 1,76 & 0,61 & 0,88 & 0,98 \\
\hline Vernonia nudiflora & 0,68 & 0,80 & 0,79 & 0,74 & 0,91 & 0,90 & 0,71 & 0,85 & 0,84 \\
\hline Oxalis perdicaria & 0 & 0 & 1,34 & 0 & 0 & 3,40 & 0 & 0 & 2,37 \\
\hline Dichondra sericea & 0,44 & 0,44 & 0,30 & 1,20 & 1,63 & 0,70 & 0,82 & 1,03 & 0,50 \\
\hline Conyza bonariensis & 0,30 & 0,39 & 0,004 & 1,47 & 2,00 & 0,20 & 0,88 & 1,19 & 0,10 \\
\hline $\begin{array}{l}\text { Demais espécies (39) com IVI } \\
\text { inferior a } 1 \text { (somatório) }\end{array}$ & 4,41 & 4,54 & 2,28 & 19,17 & 11,21 & 11,80 & 11,49 & 8,18 & 6,96 \\
\hline
\end{tabular}

A cobertura de gramíneas reptantes se reduziu entre o segundo e o terceiro levantamento, em ambas as áreas (Tab. 5-6), ao passo que não houve alteração para as gramíneas eretas. A cobertura de herbáceas também reduziu no último levantamento na subárea 1 , porém na 2 tal redução foi significativa apenas entre o primeiro e o segundo levantamento. Os subarbustos oscilaram na subárea 1 devido à existência de espécies em fase inicial de desenvolvimento no segundo levantamento, não resistindo ao período de estiagem que precedeu o terceiro levantamento. Na subárea 2, a cobertura aérea de subarbustos permaneceu semelhante entre os dois primeiros levantamentos, mas também reduziu significativamente no terceiro levantamento.

Considerando a distância da encosta nos padrões de cobertura das formas biológicas na subárea 1 , as análises apontaram diferenças apenas sobre as gramíneas eretas, indicando uma maior homogeneidade espacial para as gramíneas reptantes, herbáceas e subarbustos. A cobertura de gramíneas eretas foi maior nas unidades próximas da encosta. Espécies cespitosas costumam resistir por mais tempo a condições de sombreamento, como é o caso dos locais mais próximos da encosta, sendo então mais competitivas que as reptantes. Os arbustos e suculentas tiveram pouca representatividade na cobertura total, não possibilitando uma avaliação sobre 
Tabela 5. Riqueza, diversidade e valores médios de cobertura (\%) dos principais modos de vida das plantas, do mantilho e do solo exposto, considerando como fatores de variação o tempo (gradiente temporal) e a distância da encosta (gradiente espacial) na subárea 1, São Francisco de Assis, RS, Brasil (Médias seguidas por letras iguais não diferem significativamente $(P \leq 0,05)$ pelo teste de aleatorização; $S=$ variação da riqueza; H' = índice de Shannon; Gr. er. = gramíneas eretas; Gr. re. = gramíneas reptantes; Herb. = herbáceas; Subar. = subarbustos; Arb. = arbustos; Suc. $=$ suculentas; Man. $=$ mantilho; Solo $=$ solo exposto).

\begin{tabular}{|c|c|c|c|c|c|c|c|c|c|c|}
\hline Fator/Variável & $\mathrm{S}$ & $\mathrm{H}^{\prime}$ & Gr. er. & Gr. re. & Herb. & Subar. & Arb. & Suc. & Man. & Solo \\
\hline \multicolumn{11}{|l|}{ Tempo } \\
\hline Set./2004 & $10,34^{\mathrm{a}}$ & $1,47^{\mathrm{a}}$ & 4,75 & $28,45^{\mathrm{a}}$ & $5,34^{\mathrm{a}}$ & $1,87^{\mathrm{a}}$ & 0,31 & 0,01 & $16,28^{\mathrm{a}}$ & $43,69^{\mathrm{a}}$ \\
\hline Jan./2005 & $8,65^{\mathrm{b}}$ & $1,40^{\mathrm{a}}$ & 6,31 & $28,25^{\mathrm{a}}$ & $4,08^{\mathrm{a}}$ & $4,75^{\mathrm{b}}$ & 0,90 & 0,01 & $7,28^{\mathrm{b}}$ & $51,31^{\mathrm{b}}$ \\
\hline Maio/2005 & $7,40^{\mathrm{b}}$ & $0,99^{\mathrm{b}}$ & 3,81 & $17,69^{\mathrm{b}}$ & $2,15^{b}$ & $1,02^{\mathrm{c}}$ & 0,29 & 0,02 & $5,32^{\mathrm{b}}$ & $70,49^{\mathrm{c}}$ \\
\hline \multicolumn{11}{|l|}{ Distância encosta } \\
\hline Próximo & $10,53^{\mathrm{a}}$ & 1,34 & $7,51^{\mathrm{a}}$ & 26,93 & 3,55 & 2,56 & 0,07 & 0,04 & $5,08^{\mathrm{a}}$ & 55,44 \\
\hline Intermediário & $8,15^{\mathrm{b}}$ & 1,29 & $3,54^{\mathrm{b}}$ & 22,73 & 4,81 & 3,09 & 1,51 & 0 & $10,61^{\mathrm{b}}$ & 56,3 \\
\hline Distante & $7,67^{b}$ & 1,23 & $3,72^{\mathrm{b}}$ & 24,96 & 3,28 & 2,03 & 0 & 0 & $13,29^{\mathrm{b}}$ & 53,83 \\
\hline
\end{tabular}

Tabela 6. Riqueza, diversidade e valores médios de cobertura (\%) dos principais modos de vida das plantas, do mantilho e do solo exposto, considerando como fatores de variação o tempo (gradiente temporal) e a distância da encosta (gradiente espacial) na subárea 2, São Francisco de Assis, RS, Brasil (Médias seguidas por letras iguais não diferem significativamente $(\mathrm{P} \leq 0,05)$ pelo teste de aleatorização; $\mathrm{S}=$ variação da riqueza; H' = índice de Shannon; Gr. er. = gramíneas eretas; Gr. re. = gramíneas reptantes; Herb. = herbáceas; Subar. = subarbustos; Arb. = arbustos; Suc. $=$ suculentas; Man. $=$ mantilho; Solo $=$ solo exposto $)$.

\begin{tabular}{|c|c|c|c|c|c|c|c|c|c|c|}
\hline Fator/Variável & $\mathrm{S}$ & $\mathrm{H}^{\prime}$ & Gr. er. & Gr. re. & Herb. & Subar. & Arb. & Suc. & Man. & Solo \\
\hline \multicolumn{11}{|l|}{ Tempo } \\
\hline Set./2004 & $17,37^{\mathrm{a}}$ & $2,11^{\mathrm{a}}$ & 8,29 & $44,50^{\mathrm{a}}$ & $16,85^{\mathrm{a}}$ & $6,71^{\mathrm{a}}$ & 1,62 & 0,03 & $9,06^{\mathrm{a}}$ & $21,74^{\mathrm{a}}$ \\
\hline Jan./2005 & $13,74^{\mathrm{b}}$ & $1,96^{\mathrm{b}}$ & 7,82 & $45,78^{\mathrm{a}}$ & $9,34^{\mathrm{b}}$ & $7,43^{\mathrm{a}}$ & 2,78 & 0,03 & $6,60^{\mathrm{b}}$ & $25,00^{\mathrm{a}}$ \\
\hline Maio/2005 & $14,23^{\mathrm{b}}$ & $1,85^{\mathrm{c}}$ & 6,10 & $35,96^{\mathrm{b}}$ & $8,70^{\mathrm{b}}$ & $2,22^{\mathrm{b}}$ & 1,88 & 0,06 & $9,17^{\mathrm{a}}$ & $28,60^{\mathrm{a}}$ \\
\hline \multicolumn{11}{|l|}{ Distância encosta } \\
\hline Próximo & $16,72^{\mathrm{a}}$ & $2,14^{\mathrm{a}}$ & $8,64^{\mathrm{a}}$ & $38,38^{\mathrm{a}}$ & $16,76^{\mathrm{a}}$ & $8,35^{\mathrm{a}}$ & $3,71^{\mathrm{a}}$ & 0,04 & 8,44 & $14,69^{\mathrm{a}}$ \\
\hline Intermediário & $15^{\mathrm{b}}$ & $2,01^{\mathrm{b}}$ & $9,06^{\mathrm{a}}$ & $48,92^{\mathrm{b}}$ & $8,73^{\mathrm{b}}$ & $4,48^{\mathrm{ab}}$ & $2,44^{\mathrm{a}}$ & 0,08 & 8,36 & $21,97^{\mathrm{b}}$ \\
\hline Distante & $13,6^{\mathrm{b}}$ & $1,77^{\mathrm{c}}$ & $4,65^{b}$ & $39,52^{\mathrm{a}}$ & $9,16^{\mathrm{b}}$ & $3,44^{\mathrm{b}}$ & $0,17^{\mathrm{b}}$ & 0 & 8,02 & $38,42^{\mathrm{c}}$ \\
\hline
\end{tabular}

os padrões de distribuição.

Na subárea 2, a diminuição da participação das gramíneas eretas ocorreu apenas nas unidades mais distantes da encosta. De modo similar, as coberturas de herbáceas, arbustos e subarbustos foram maiores nas unidades próximas da encosta. Este padrão reforça a importância da cobertura arbórea existente na encosta para a manutenção da diversidade de espécies e da cobertura do solo. Por outro lado, as gramíneas reptantes apresentaram maior cobertura nos quadros situados a uma distância intermediária da encosta. A menor cobertura das demais formas de vida estaria aparentemente favorecendo as reptantes, porém nos quadros mais distantes, houve maior percentagem de solo exposto e menor cobertura de reptantes.

A cobertura de mantilho apresentou diferença significativa com relação à distância da encosta (menor nas parcelas próximas da encosta) e ao período do levantamento na subárea 1 (maior no primeiro levantamento). Na subárea 2, houve menor cobertura do mantilho apenas no segundo levantamento. Essas variações devem estar relacionadas à ocorrência das chuvas torrenciais e ao efeito contínuo do vento, pois promovem a remoção do material morto sobre o solo. A principal contribuição da presença do mantilho seria para a elevação da quantidade de matéria orgânica no solo.

Dentre as dez variáveis avaliadas, solo exposto foi a que apresentou maior amplitude de variação, indicando pleno processo de arenização em ambas as áreas de estudo. Na subárea 1, a distância da encosta não foi um fator de variação, uma vez que o processo de arenização ocorria em praticamente toda a extensão da área. No entanto, houve variação significativa ao longo do tempo. No primeiro levantamento havia menos solo exposto e sua cobertura foi aumentando progressivamente no início, atingindo um valor consideravelmente alto no último $(43,38 ; 49,80$ e $70 \%$, respectivamente). Essa variação abrupta coincide com o período pós-estiagem, seguido por chuvas torrenciais na região, indicando a influência destes fatores como desencadeadores da expansão dos areais em áreas fragilizadas pelo relevo e pelo uso contínuo do campo nativo como pastagem. 
Na subárea 2, com maior cobertura vegetal, o solo exposto apresentou variação espacial conforme a distância da encosta, ocupando menor porção da área nas proximidades da encosta, maior nas unidades intermediárias, atingindo o maior valor nas distantes $(38,4 \%)$, que é ainda menor que o primeiro valor de cobertura da subárea 1. Há um aparente favorecimento da cobertura arbórea da encosta do relevo tabular sobre a estabilidade da cobertura vegetal nas áreas mais próximas ao cerro na subárea 2. Conforme o aumento da distância da encosta, reduzem-se as condições para que os formas biológicas mantenham sua cobertura, aumentando assim o solo exposto.

Os resultados diretos das análises de variância, associados com a interpretação dos fatores abióticos de solo e pluviosidade, indicaram que a dinâmica de avanço dos areais depende de um conjunto de fatores locais (relevo, solo, vegetação, pisoteio do gado) interagindo com as flutuações de variáveis climáticas (chuva, vento, insolação).

A flora dos campos do sudoeste do RS, com arenização, apresentou significativa riqueza de espécies (102). Tal riqueza variou e diminuiu consideravelmente em áreas com processo avançado de arenização. Avaliando as comunidades, as espécies dominantes são gramíneas reptantes, ou seja, espécies rizomatosas de hábito prostrado, representadas principalmente por Paspalum stellatum, P. nicorae e P. notatum. Tal dominância caracteriza a fisionomia de campos limpos, que é determinada, principalmente, pelo pastoreio contínuo do gado.

As características pedológicas influenciaram diretamente na cobertura vegetal das áreas estudadas. A maior estabilidade encontrada na subárea 2 pode ser relacionada a três fatores: maior fertilidade do solo, cobertura arbórea na encosta do cerro e maior cobertura inicial de vegetação campestre. A presença da cobertura florestal na porção da encosta adjacente à subárea 2 influenciou na formação de uma cobertura campestre mais estável ao longo do tempo e em maior proporção em relação à subárea 1 , provavelmente devido às condições de menor insolação, maior umidade e amenização do efeito das chuvas torrenciais sobre a superfície do solo. Entretanto, o processo de arenização também ocorreu na subárea 2, afinal foi observado um aumento na cobertura de solo exposto com a distância da encosta, além da pouca matéria orgânica e baixo teor de argila encontrado no solo local. Na subárea 1 , o avanço da arenização foi evidente e acelerado no decorrer do período de avaliação, pela pouca cobertura vegetal da encosta, pelo solo de baixa fertilidade, associado ao pisoteio do gado e às chuvas torrenciais, constituindo-se nos principais fatores desencadeadores do processo de arenização.
Os campos do sudoeste do RS com tendência à arenização exigem cuidados especiais. A utilização desses solos para fins econômicos deve atender manejos específicos, entre os quais destaca-se a manutenção da cobertura nativa de campo com índice moderado de uso com gado extensivo (lotação baixa). Em áreas já atingidas pela arenização, é imprescindível que haja o isolamento da área, a fim de possibilitar o incremento da vegetação com espécies adaptadas às condições de baixa fertilidade e retenção de água pelo solo e resistentes à agressão da areia carregada pelo vento. Técnicas como revegetação dos areais, cultivo mínimo, rotação de culturas e o aporte de nutrientes, quando empregadas, devem ser associadas com adubação verde e técnicas que minimizem as perdas por lixiviação. Qualquer técnica deve prever a maior cobertura do solo e conseqüente aumento da matéria orgânica, manutenção de umidade e retenção das águas das chuvas (Azevedo \& Kaminski 1995), preferencialmente antes do início do processo de arenização.

É preciso aprofundar o conhecimento sobre a composição florística e fitossociológica da vegetação de outras áreas de campos com arenização no sudoeste do RS. Tal conhecimento poderá contribuir na compreensão do processo de arenização e na elaboração de uma lista das espécies que possam ser utilizadas na restauração ecológica das áreas atingidas. Além disso, o subsídio em programas de restauração e a determinação de áreas frágeis deveriam ser considerados para preservação dessas formações campestres.

\section{Agradecimentos}

Aos programas de pós-graduação de Geografia e Botânica da Universidade Federal do Rio Grande do Sul (UFRGS), pelo incentivo e oportunidades para a realização desta pesquisa; ao Museu de Ciências Naturais do Centro Universitário Univates, pelo espaço para a realização do trabalho de identificação das espécies; a todos os colegas e amigos que auxiliaram nos trabalhos de campo e na identificação das espécies.

\section{Referências bibliográficas}

APG II - Angiosperm Phylogeny Group. 2003. An update of the Angiosperm Phylogeny Group classification for the orders and families of flowering plants. Botanical Journal of the Linnean Society 141: 399-436.

Azevedo, A.C. \& Kaminski, J. 1995. Considerações sobre os solos dos campos de areia no Rio Grande do Sul. Ciência \& Ambiente 11: $65-70$.

Basso, L.B. \& Verdum, R. 2006. Qualidade das águas em bacias hidrográficas com focos de arenização, sudoeste do Rio Grande do Sul. Caderno Prudentino de Geografia 28: 45-55.

Boldrini, I.I. 1997. Campos do Rio Grande do Sul: Caracterização Fisionômica e Problemática Ocupacional. Boletim do Instituto de Biociências 56: 1-39. 
Boldrini, I.I. \& Eggers, L. 1996. Vegetação campestre do sul do Brasil: Dinâmica de espécies à exclusão do gado. Acta Botanica Brasilica 10: 37-50.

Boldrini, I.I.; Miotto, S.T.S.; Longhi-Wagner, H.M.; Pillar, V.D. \& Marzall, K. 1998. Aspectos florísticos e ecológicos da vegetação campestre do Morro da Polícia, Porto Alegre, RS, Brasil. Acta Botanica Brasilica 12: 89-100.

EMBRAPA. 1999. Sistema Brasileiro de classificação de solos. Rio de Janeiro, Embrapa - Centro Nacional de Pesquisas de Solos.

IBGE. 2004. Mapa da vegetação do Brasil e Mapa de Biomas do Brasil. http://www.ibge.gov.br (Acesso em: 23/02/2007).

Klamt, E. \& Schneider, P. 1995. Solos suscetíveis à erosão eólica e hídrica na região da Campanha do Rio Grande do Sul. Ciência \& Ambiente 11: 71-80.

Langevelde, F.V.; Van de Vijver, C.A.D.M.; Kumar, L.; Koppel, J.V.D.; Ridder, N.D.; Andel, J.V.; Skidmore, A.K.; Hearne, J.W.; Stroosnijder, L.; Bond, W.J.; Prins, H.H.T. \& Rietkerk, M. 2003. Effects of fire and herbivory on the stability of savanna ecosystems. Ecology 84: 337-350.

Leps, J.; Osbornová-Kosinová, J. \& Rejmánek, M. 1982. Community stability, complexity and species life history strategies. Vegetatio 50: $53-63$.

Lindman, C.A.M. 1906. A vegetação do Rio Grande do Sul. Porto Alegre, Livraria Echenique.

Manly, B.F.J. 1997. Randomization, bootstrap and Monte Carlo methods in biology. London, Chapman \& Hall.

Marchiori, J.N.C. 1992. Areais no sudoeste do Rio Grande do Sul: elementos para uma História Natural. Ciência \& Ambiente 03: 65-89.

Marchiori, J.N.C. 1995. Vegetação e areais no sudoeste rio-grandense. Ciência \& Ambiente 11: 53-64.

Matteuci, S.D. \& Colma, A. 1982. Metodologia para el estudo de la vegetacion. Washington, Secretaria General de la Organización de los Estados Americanos.

Medeiros, E.; Robaina, L.E. \& Cabral, I.L.L. 1995. Degradação Ambiental na Região Centro-oeste do Rio Grande do Sul. Ciência \& Ambiente 11: 53-64.

Mueller-Dombois, D. \& Ellenberg, H. 1974. Aims and methods of vegetation ecology. New York, John Willey \& Sons.

Nimer, E. 1979. Climatologia do Brasil. Rio de Janeiro, IBGE Superintendência de Recursos Naturais e Meio Ambiente.
Overbeck, G.E.; Müller, S.C.; Pfadenhauer, J. \& Pillar, V.D. 2006. Floristic composition, environmental variation and species distribution patterns in a burned grassland in southern Brazil. Brazilian Journal of Biology 66: 1073-1090.

Overbeck, G.E.; Müller, S.C.; Fidelis, A.; Pfadenhauer, J.; Pillar, V.D.; Blanco, C.C.; Boldrini, I.I.; Both, R. \& Forneck, E.D. 2007. Brazil's neglected biome: The South Brazilian Campos. Pp. 101-116. In: Perspectives in Plant Ecology, Evolution and Systematics 9.

Pielou, E.C. 1969. An introduction to mathematical ecology. New York, Wiley-Interscience.

Pillar, V.D. 2004. MULTIV software para análise multivariada, testes de aleatorização e autoreamostragem "bootstrap" 2.3.9. http://ecoqua.ecologia.ufrgs.br (Acesso em: 8/08/2006).

Pillar, V.D. \& Orlóci, L. 1996. On randomization testing in vegetation science: multifactor comparisons of relevé groups. Journal of Vegetation Science 7: 582-592.

Rambo, B. 1956. A fisionomia do Rio Grande do Sul. Porto Alegre, Selbach.

Comissão de Química e Fertilidade do Solo. 2004. Manual de adubação e de calagem para os Estados do Rio Grande do Sul e de Santa Catarina. Porto Alegre, Sociedade Brasileira de Ciência do Solo - Núcleo Regional Sul.

Smith, L.B.; Wasshausen, D.C. \& Klein, R.M. 1982. Gramíneas. Pp. 909-1407 In: P. Reitz. Flora Ilustrada Catarinense. Itajaí, Herbário "Barbosa Rodrigues".

Suertegaray, D.M.A. 1995. O Rio Grande do Sul descobre os seus “desertos". Ciência \& Ambiente 11: 33-52.

Suertegaray, D.M.A. 1998. Deserto Grande do Sul: controvérsia. Porto Alegre, Editora da UFRGS.

Suertegaray, D.M.A.; Guasselli, L.A. \& Verdum, R. (orgs.). 2001. Atlas da Arenização: Sudoeste do Rio Grande do Sul. Porto Alegre, Secretaria da Coordenação e Planejamento.

Verdum, R. 2004. Depressão Periférica e planalto. Potencial ecológico e utilização social da natureza. In: R. Verdum; L.A. Basso \& D.M.A. Suertegaray (orgs.). Rio Grande do Sul: paisagens e territórios em transformação. Porto Alegre, Editora da UFRGS.

Whittaker, R.H. 1972. Evolution and measurement of species diversity. Taxon 21: 213-251. 